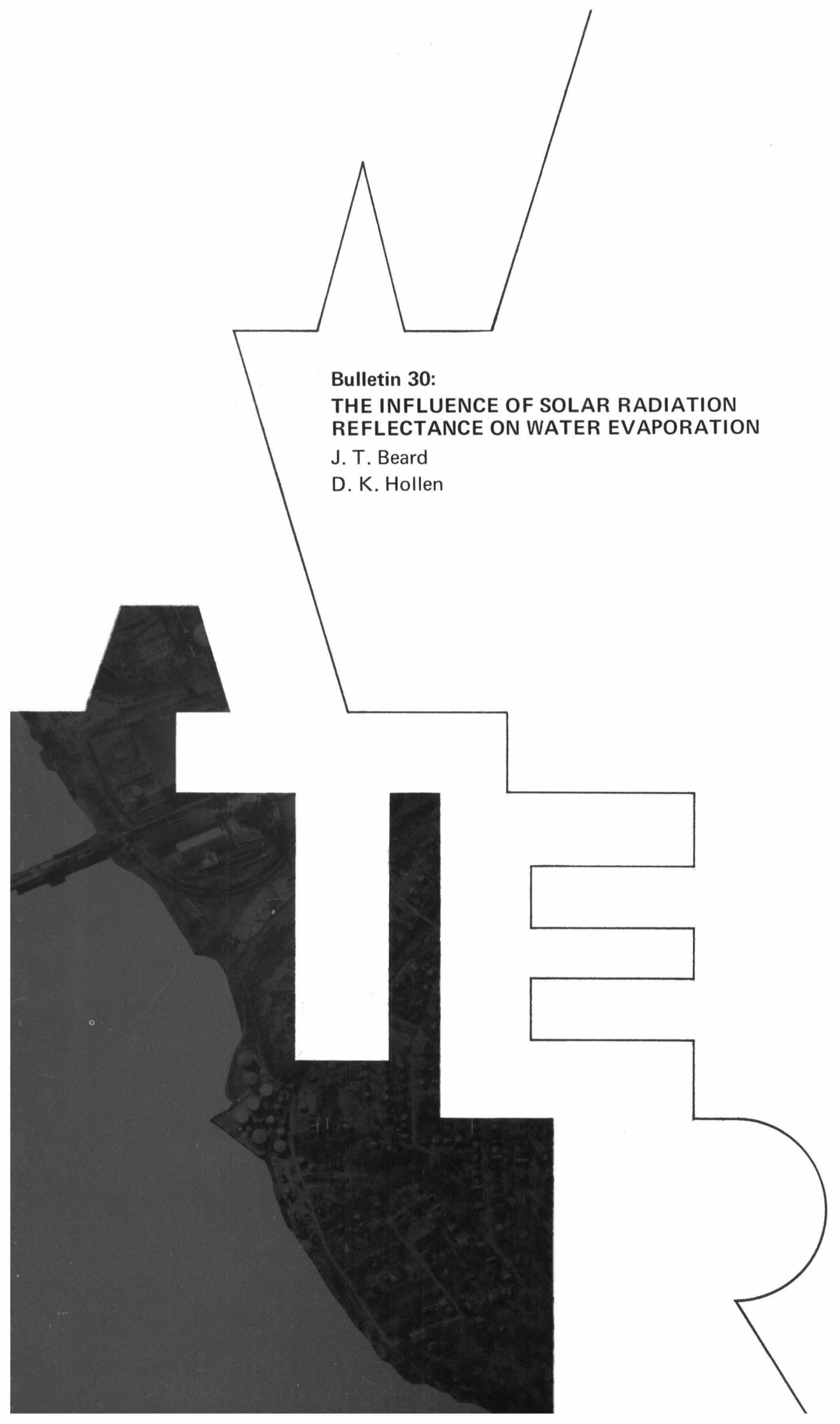




\title{
THE INFLUENCE OF SOLAR RADIATION REFLECTANCE ON WATER EVAPORATION
}

\author{
J. Taylor Beard \\ Associate Professor of Mechanical Engineering \\ University of Virginia \\ and \\ David K. Hollen \\ Graduate Student of Mechanical Engineering \\ University of Virginia
}

The work upon which this report is based was supported in part by funds provided by the United States Department of the Interior, Office of Water Resources Research, as authorized under the Water Resources Act of 1964.

\author{
Water Resources Research Center \\ Virginia Polytechnic Institute \\ Blacksburg, Virginia \\ August 1969
}




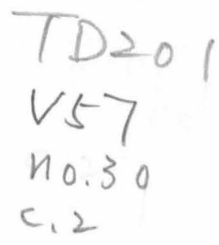




\section{PREFACE}

The evaporation of a water reservoir may be reduced by increasing the reflectance of solar energy by the water surface. Such a change in reflectance will require surface modification such as the application of a special surface film or monolayer which has good reflecting properties. The amount of evaporation suppression will depend also on the changes in diffusion coefficient and shear stress which will accompany surface modifications.

The transient energy equation was applied to an element of a water surface. Numerical methods were used to solve the equation with the aid of a digital computer. An evaluation of the various energy terms were required for this analysis. These terms included conduction and convection heat transfer, the absorbed solar energy, the long-wave radiant energy exchange, the energy associated with evaporation, and the transient storage of energy.

The analytical model gave an average evaporation suppression by cetyl alcohol to be 22.6 percent. This is consistent with the experimental work of Crow (2) who indicated a 25 percent reduction.

Results for monolayers with hypothetical reflectance properties and with the diffusion properties of a cetyl alcohol monolayer showed average evaporation reductions of $25 \%$ to $45 \%$, depending on the reflection properties selected. 



\section{TABLE OF CONTENTS}

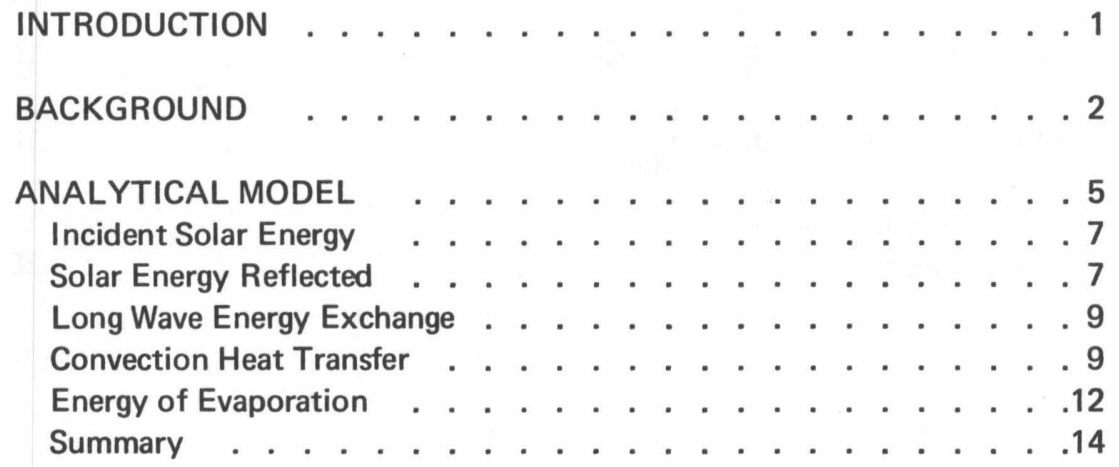

RESULTS . . . . . . . . . . . . . . . . . . . . 15

CONCLUSIONS AND RECOMMENDATIONS . . . . . . . . . . . . .

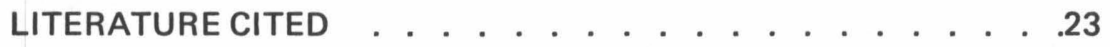

ACKNOWLEDGMENTS . . . . . . . . . . . . . . . 26 


\section{LIST OF TABLES}

Table 1. Water Surface Reflectance ． . . . . . . . . . . . . . .10

Table 2. Water Evaporation $\frac{\text { inches }}{\text { day }}$. . . . . . . . . . . . . . . . . . . 18

Table 3. Percent of Evaporation

Reduction . . . . . . . . . . . . . . . . . . . . . . . 20 


\section{LIST OF FIGURES}

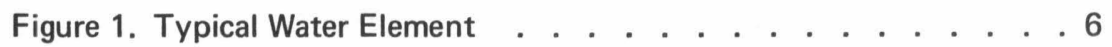

Figure 2. Incident Solar Radiation

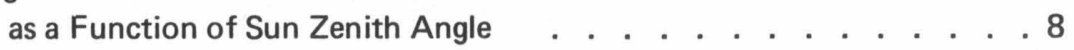

Figure 3. Temperatures for a Winter Day . . . . . . . . . . . . 16

Figure 4. Average Annual Evaporation

Reduction as a Function of Normal

Reflectance Ratio . . . . . . . . . . . . . . . . . . . . 19 


\section{INTRODUCTION}

The desire to reduce water evaporation has caused an increasing research effort in recent years because of the great demand for water and the decrease in supply available.

An example is presented to support the concern for water reservoir evaporation. Annual gross evaporation from Lake Mead, the Nation's largest reservoir, ranged from 699,000 to 875,200 acre feet during the water years 1953-1956. The annual water lost by evaporation from this one reservoir is greater than the total capacity of most reservoirs in the United States (1). If water evaporation can be reduced, the total supply of water available for use will be increased and also the quality of the water will be improved since evaporation removes only pure water.

Several methods suggested by investigators for reducing water evaporation are: oil films spread on the water surface, a plastic cover constructed over the water surface, underground reservoirs, barriers for reducing surface winds and monomolecular films. The last of these suggestions, commonly known as monolayers, has received the most study in recent years. The molecules of a monolayer are long chain hydrocarbons and upon contact with water form an oriented layer, one molecule thick. A monolayer of cetyl alcohol was reported to reduce evaporation from a pond by 39.4 percent (2). Also, suppressing evaporation from water storages by monolayers is the most economical of all methods of conserving water that are now available (3).

Monolayers act as diffusion barriers and also damp out the small waves found on a reservoir surface. In 1966, Beard and Wiebelt (4) showed that monolayers affect the reflectance of solar and sky energy by acting as an optical thin film coating which may increase reflectance depending on the optical properties.

The purpose of this study is to investigate analytically the effect film reflectance of solar energy has on water evaporation. Analytical results show how ideal chemical films with different reflectance properties influence the amount of evaporation. 


\section{BACKGROUND}

A great deal of work has been done since Dalton first established relationship for the evaporation process. Dalton's equation states that:

$$
E=K_{e} U\left(P_{s}-P_{a}\right)
$$

where:

$\mathrm{K}_{\mathrm{e}} \quad=$ a lumped constant influenced by air conditions

$\mathrm{U} \quad=$ wind velocity

$\mathrm{P}_{\mathrm{S}} \quad$ = saturated vapor pressure at water surface temperature

$P_{\mathrm{a}} \quad=$ partial vapor pressure at air temperature

$\mathrm{E} \quad$ = evaporation

Many investigators $(5,6,7,8)$ have attempted to determine analytical and experimental techniques for conveniently predicting evaporative loss and the various parameters which influence it.

One investigator made a steady state assumption and showed that the daily convective heat transfer should be proportional to the evaporation rate (9). This ratio was later called the Bowen ratio and is written as follows:

$$
R_{B}=c \frac{t_{s}-t_{a}}{P_{s}-P_{a}} \frac{P}{760}
$$

where:

$$
\begin{aligned}
& t_{s} \quad=\text { water surface temperature } \\
& t_{a} \quad=\text { air temperature } \\
& P_{S} \quad=\text { saturated vapor pressure of water surface } \\
& P_{a} \quad=\text { vapor pressure of air }
\end{aligned}
$$




$$
\begin{aligned}
& \mathbf{P} \quad=\text { atmospheric pressure } \\
& \text { C } \quad \text { a constant }
\end{aligned}
$$

Other investigators have developed models based on assumptions of particular types of air flow over the water surface $(10,11)$ and upon form of the radiant energy exchange between the sun and the water and between the sky and the water $(12,13)$.

As part of a report for the U.S. Geological Survey (14), Anderson performed extensive work on the energy-budget method for determining evaporation at Lake Hefner in Oklahoma City, Oklahoma. Anderson used the following energy-budget equation in determining lake evaporation:

$$
Q_{s} \cdot Q_{r} \cdot Q_{b}-Q_{h}-Q_{e}+Q_{v}^{\prime}=Q_{\rho}
$$

where:

$$
\begin{aligned}
& Q_{s}=\text { solar radiation incident on water surface } \\
& Q_{r}=\text { reflected solar radiation } \\
& Q_{b}=\text { net long-wave energy exchange } \\
& Q_{h}=\text { energy convected from the body of water to the atmosphere } \\
& Q_{e}=\text { energy utilized for evaporation } \\
& Q_{v}^{\prime}=\text { net energy advected into the body of water } \\
& Q_{\rho} \quad=\text { the increase in energy stored in the body of water. }
\end{aligned}
$$

Various techniques were used to evaluate the above terms that influence evaporation.

The report concluded that the energy-budget method for determining evaporation is valid provided that energy storage terms are considered. In addition the report indicated that for purposes of evaporation determination empirical evaluations are inadequate for atmospheric radiation, and considerable controversy still exists over the meaning and validity of Bowen's ratio. 
Further evaporation studies have been reported for work at Lake Mead (15) and Lake Erie (16).

It had been well established that certain monomolecular films applied to water surfaces will retard evaporation. Also, it has been shown that if films with certain optical properties are available, they should significantly increase the reflectance of solar energy (4). If the net radiant energy input to a body of water is reduced, then the evaporation will also be reduced, as will be shown in the following paragraphs. 


\section{ANALYTICAL MODEL}

An analytical model was developed for determining the daily evaporation rate from a water surface under two different conditions. The first condition assumed the water surface to behave in a typical fashion. The second condition assumed that the water surface was covered by various hypothetical films having optical properties which result in increased solar energy reflectance. In addition the films were considered to have the diffusion properties of a cetyl alcohol monolayer (to act as a diffusion barrier).

The model considered that an element of a typical water reservoir undergoes transient energy exchange resulting from the variation of radiation, convection and evaporation heat transfer with the time of day. It is assumed that the water element behaved as a slab undergoing conduction, when the water temperature decreases with depth (no buoyancy effects) and that it behaves as a mixing medium undergoing free convection heat exchange, when temperature increases with depth (buoyancy effects).

As is shown in Figure 1, the element of water was divided into various subvolumes or nodes. This was done so that the conduction equation:

$$
\frac{\partial t}{\partial \theta}=\alpha \frac{\partial^{2} t}{\partial z^{2}}
$$

could be solved numerically by standard techniques (17), as illustrated below.

Equations were written to express the temperature of each internal nodal point at a future time as a function of its present temperature and the present temperature of adjacent nodes. Conservation of energy for each subvolume or node provides that the net energy conducted into a node during a unit of time, $\Delta \theta$ be equal to the change in internal energy.

$$
\begin{aligned}
& Q_{1 \rightarrow 2}+Q_{3 \rightarrow 2}=Q_{\text {STORED }} \\
& k(\delta \times 1) \frac{\left(t_{1}-t_{2}\right)}{\delta} \Delta \theta+k(\delta \times 1) \frac{\left(t_{3}-t_{2}\right)}{\delta} \Delta \theta \\
& =c_{p} \rho V\left(t_{2}{ }^{\prime}-t_{2}\right),
\end{aligned}
$$




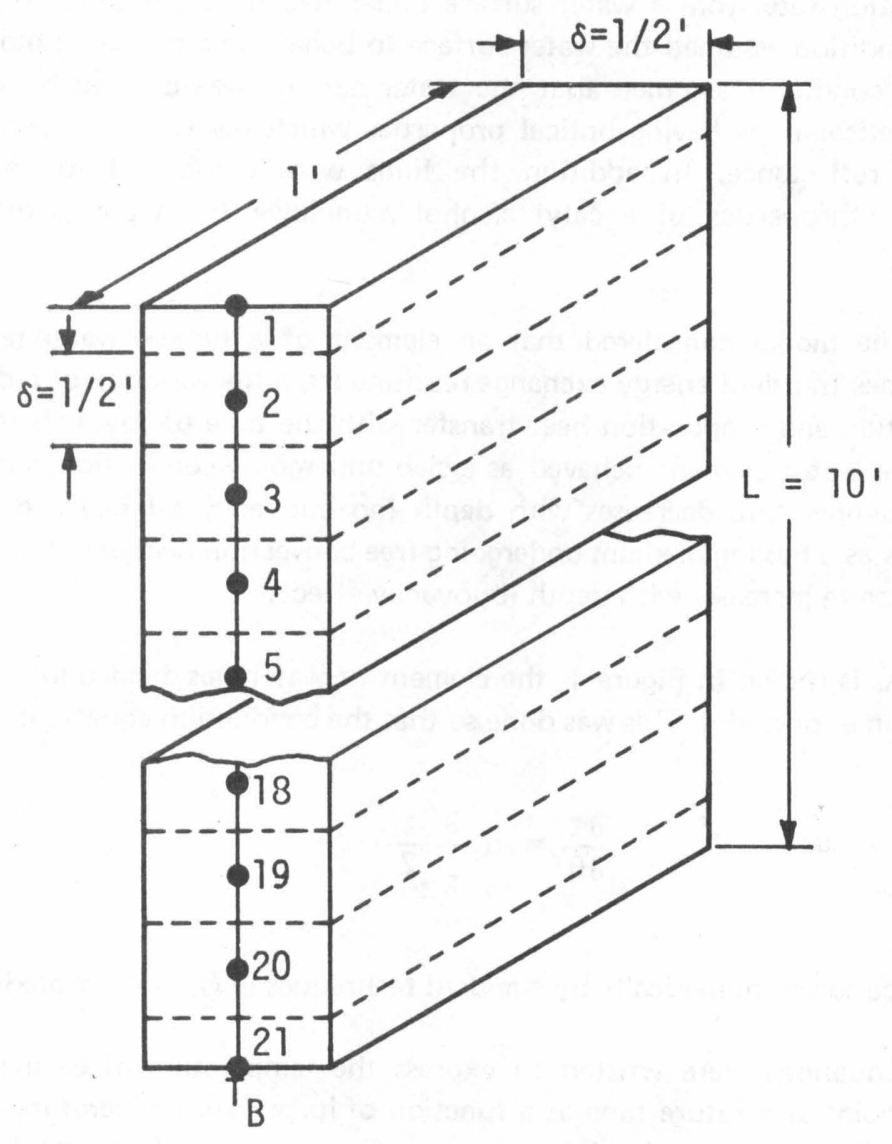

Figure 1. Typical Water Element 
where $t_{2}{ }^{\prime}$ is the future temperature at the end of a finite time interval $\Delta \theta$, and $\mathrm{V}$ is the volume of water containing the node in question. Solving the equation for $\mathrm{t}_{2}$, one obtains:

$$
t_{1}-2 t_{2}+t_{3}=\frac{c_{p} \rho V}{k \Delta \theta}\left(t_{2}{ }^{\prime}-t_{2}\right) .
$$

Evaluation of the equation for the surface node is more complex because of the various energy terms which influence energy exchange at the upper surface. (See description of Anderson's work on energy budget). A thorough description of the energy terms at the boundary has been presented by Hollen (18). A brief description of these terms follows.

\section{Incident Solar Energy}

The solar energy reaching a surface at the outer fringes of the earth's atmosphere is about $440 \mathrm{Btu} / \mathrm{hr}^{-\mathrm{ft}^{2}}$. However, less solar energy reaches the earth because part of it is absorbed and scattered as it passes through the air, water vapor, and dust that surrounds the earth.

In a report to the U.S. Bureau of Reclamation, Wiebelt and Beard (19) presented tabulations of incident solar energy as a function of the above variables. The present analysis used these tabulations and assumed that the condition under which water element exists is described by:

$$
\begin{aligned}
& \text { Pressure }=760 \mathrm{~mm} \text { of } \mathrm{Hg} \\
& \text { Water Vapor }=40 \mathrm{~mm} \text { precipitable } \\
& \text { Dust }=300 \text { particles } / \mathrm{cc} .
\end{aligned}
$$

Figure 2 shows a graph of the solar radiation incident on the earth as it varies with the sun zenith angle $\beta$.

\section{Solar Energy Reflected}

The amount of solar energy reflected by the water is equal to the incident solar energy times the water reflectance. One notes that each of these depends on the solar zenith angle, $\beta$, or the time of day. 


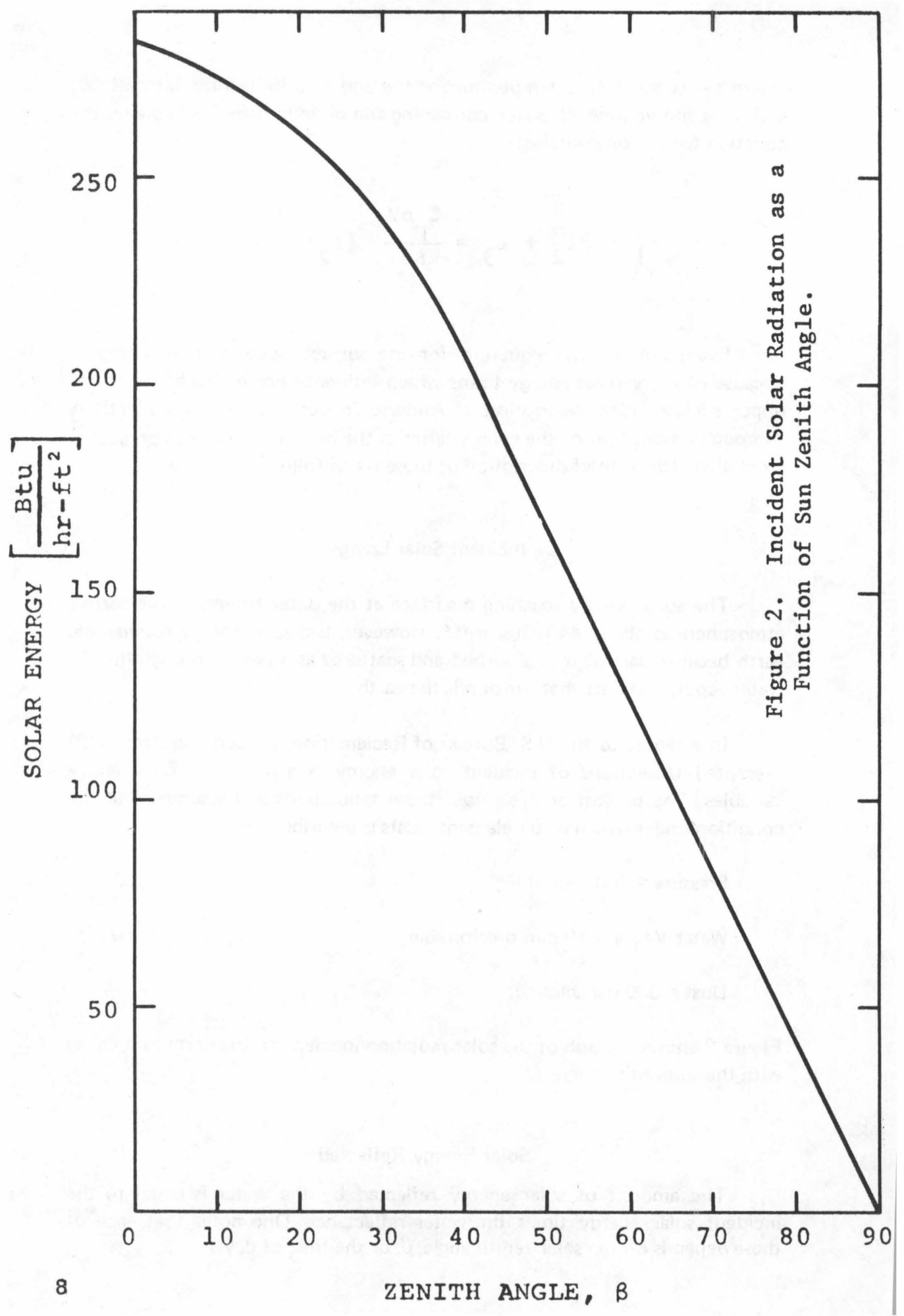


Anderson (14), reporting in the Lake Hefner study, gave the following empirical equation describing his reflectance data:

$$
R_{t}=a \phi^{b}
$$

where:

$$
\begin{aligned}
& \mathrm{R}_{\mathrm{t}} \quad=\text { reflectance } \\
& \mathrm{a} \quad=1.18 \\
& \phi \quad=\text { angle the sun makes with the horizon, }\left(90^{\circ}-\beta\right) \\
& \mathrm{b} \quad=-0.77
\end{aligned}
$$

This equation is used as an approximation for reflectance of solar energy from plain water surfaces.

Upon the application of a reflecting monolayer the above equation obviously changes. Data for the reflectance of various hypothetical monolayers (4) can be fitted to the general form. Typical examples are illustrated in Table I.

\section{Long Wave Energy Exchange}

It can be shown that the long wave energy exchange can be approximated by assuming the sky to be a black body at the ambient temperature, $T_{a}$, and the water to be a gray emitter at the surface temperature, $\mathrm{T}_{\mathrm{S}}$. This gives:

$$
\mathrm{Q}_{\mathrm{b}}=\epsilon \sigma\left(\mathrm{T}_{\mathrm{S}}-\mathrm{T}_{\mathrm{a}}\right) \text {, }
$$

where $\sigma$ is the Stefan Boltzmann constant and $\epsilon$ is the emissivity of water, calculated by Hollen to be $\mathbf{0 . 9 2 2}$. The ambient temperature is considered to vary as a known sine wave over a 24 hour period.

\section{Convection Heat Transfer}

Convection heat transfer is described by the equation: 


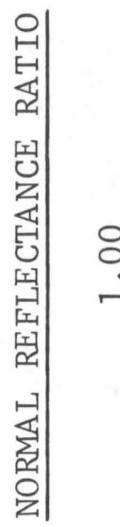

• 兵

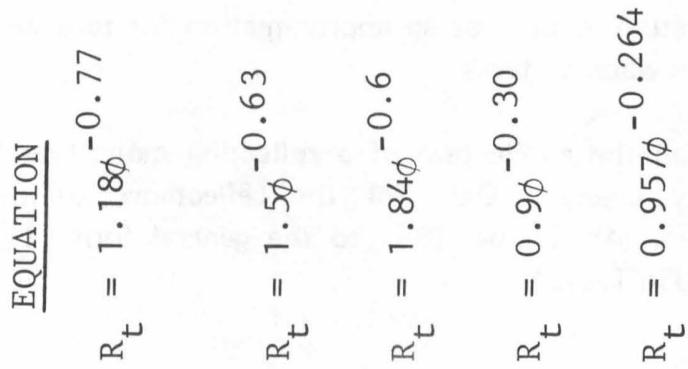

留留

$\begin{array}{llll}\infty & 0 & m & \infty \\ \dot{m} & m & m & \infty\end{array}$

•

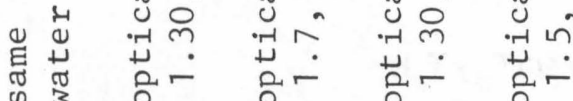

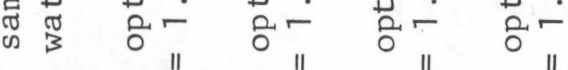

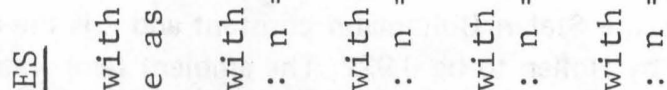

$\begin{array}{llllllllll}H & 0 & \beta & 0 & \beta & \ddot{1} & \beta & \ddot{1} & \beta & \ddot{1}\end{array}$

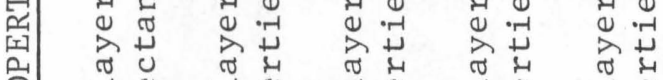

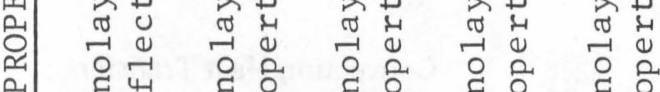

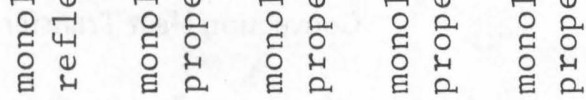




$$
\mathrm{Q}_{\mathrm{h}}=\mathrm{h}\left(\mathrm{T}_{\mathrm{S}}-\mathrm{T}_{\mathrm{a}}\right) \text {, }
$$

where $h$ is the convective coefficient, and $T_{a}$ is the ambient temperature.

A search of the literature found no established relationship for estimating the convective coefficient, h. However, it was assumed that the Reynold's analogy for turbulent flow over a flat plate could be used to relate $\mathrm{h}$ to shear stress and air properties:

$$
h=\frac{g_{c} \tau}{U_{a}}\left[c_{p}\left(\frac{k_{a}}{\mu}\right)^{2}\right]^{1 / 3}
$$

where:

$$
\begin{aligned}
& \tau \quad=\text { surface shear stress } \\
& \mathrm{U}_{\mathrm{a}} \quad=\text { air velocity } \\
& \mathrm{C}_{\mathrm{p}} \quad=\text { specific heat at constant pressure of air } \\
& \mathrm{k}_{\mathrm{a}} \quad=\text { thermal conductance of air } \\
& \mu \quad=\text { absolute viscosity of air }
\end{aligned}
$$

Keulegan (20), Fitzgerald (21), and Hutchinson (22) have presented studies on the variation of surface shear stress with wind velocity, and an average of their results was used (18):

For rough water:

$$
\tau=\frac{1}{g_{C}} 28.2 \times 10^{-4} \rho_{A} U^{2},
$$

and for monolayer-covered, smooth water: $\tau=\frac{1}{g_{c}} 19.75 \times$ $10^{-4} \rho_{A} U^{2}$ 
Making the above substitutions one can show that $h$ varies from 1.5 to 6.7 $\left[\mathrm{Btu} / \mathrm{hr}-\mathrm{ft}^{2{ }^{\circ} \mathrm{F}}\right.$ ] with wind speeds varying from 7 to $14 \mathrm{mph}$.

\section{Energy of Evaporation}

The Bowen ratio is not a constant when one considers transient heat transfer. Therefore the energy of evaporation must be calculated separately:

$$
\mathrm{Q}_{\mathrm{e}}=\mathrm{h}_{\mathrm{fg}} \dot{\mathrm{m}},
$$

where $h_{f g}$ is the latent heat of vaporization and $m$ is the evaporation mass flux in $\left[\mathrm{lb}_{\mathrm{m}} / \mathrm{hr}-\mathrm{ft}^{2}\right]$. The mass flux can be written similarly to the convection heat transfer equation:

$$
m=h_{D}\left(C_{w} \cdot C_{a}\right) \text {, }
$$

where:

$$
\begin{aligned}
& h_{D}=\text { mass-transfer coefficient } \\
& C_{w}=\text { concentration of water vapor diffusing into the air } \\
& C_{a}=\text { Concentration of water vapor in the air }
\end{aligned}
$$

Assuming water vapor and air behave as ideal gasses, the concentration terms can be written:

$$
C_{w}-C_{a}=\frac{M_{w}}{R_{0} T}\left(P_{w}-P_{a}\right),
$$

where:

$$
\begin{aligned}
& P_{\mathbf{w}} \quad=\text { saturated water vapor pressure } \\
& P_{a} \quad=\text { partial vapor pressure in air. }
\end{aligned}
$$

The mass transfer coefficient is determined by extending Reynolds analogy by the heat-mass analogy. This gives: 


$$
h_{D}=\frac{h}{\rho_{A} C_{P}(\alpha / D)^{2 / 3}}
$$

where:

$$
\begin{aligned}
& C_{p}=\text { heat capacity } \\
& a \quad=\text { thermal diffusivity of air } \\
& D \quad=\text { diffusion coefficient of water vapor into air. }
\end{aligned}
$$

Consequently, if one makes the above substitutions, the energy associated with evaporation is a known function of vapor pressures (which is a simple function of temperature) and the diffusion coefficient. The value of the diffusion coefficient depends on the presence or absence of a monolayer. The diffusion coefficient for water vapor into air is given by Eckert and Drake (23) to be:

$$
D=0.892 \frac{P_{0}}{T}\left[\frac{T_{S}}{T_{0}}\right]^{1.81}
$$

where:

$$
\begin{aligned}
& D \quad=\text { diffusion coefficient, } \mathrm{ft}^{2} / \mathrm{hr} \\
& P_{O}=14.22 \mathrm{lb} / \mathrm{in}^{2} \\
& T_{O} \quad=460^{\circ} \mathrm{R} \\
& P \quad=\text { atmospheric pressure taken as } 14.7 \mathrm{lb} / \mathrm{in}^{2} .
\end{aligned}
$$

Making the above substitutions into the above equation, the expression for diffusion is reduced to: 


$$
D=0.863\left[\frac{t_{s}+460}{460}\right]^{1.81}
$$

where $\mathrm{t}_{\mathrm{S}}$ is in Fahrenheit degrees.

As a cetyl alcohol monolayer is known to act as a diffusion barrier by reducing evaporation up to $39 \%$, it was assumed that the diffusion coefficient should be reduced by $39 \%$ when a monolayer was assumed present.

\section{Summary}

Each of the above energy relations is a function of the temperature of the water surface, which is considered to be an unknown. However, by making an initial temperature assumption and by performing an iterative numerical methods technique both the daily temperature history and the amount of evaporation can be computed. 


\section{RESULTS}

Evaporation and temperature histories were calculated for weather conditions of a typical day during the four seasons of the year: The conditions used were:

\section{$\underline{\text { Winter }}$}

Water temperature at $Z=10 \mathrm{ft}: \mathrm{T}_{\mathrm{B}}=38^{\circ} \mathrm{F}$

Daily mean air temperature: $\mathrm{T}_{\mathrm{m}}=34^{\circ} \mathrm{F}$

Deviation from mean temperature to high and low: $\mathrm{T}_{\text {amp }}=7^{\circ} \mathrm{F}$

Relative humidity $=30 \%$

Wind velocity $=15 \mathrm{ft} / \mathrm{sec}$

Number of daylight hours $=10$

\section{Spring and Fall}

Water temperature at $Z=10 \mathrm{ft}: \mathrm{T}_{\mathrm{B}}=65^{\circ} \mathrm{F}$

Daily mean air temperature: $\mathrm{T}_{\mathrm{M}}=60^{\circ} \mathrm{F}$

Deviation from mean temperature to high and low: $\mathrm{T}_{\mathrm{amp}}=12^{\circ} \mathrm{F}$

Relative humidity $=50 \%$

Wind velocity $=15 \mathrm{ft} / \mathrm{sec}$

Number of daylight hours $=12$

\section{Summer}

Water temperature at $Z=10 \mathrm{ft}: T_{B}=75^{\circ} \mathrm{F}$

Daily mean air temperature $\mathrm{T}_{\mathrm{M}}=76^{\circ} \mathrm{F}$ 


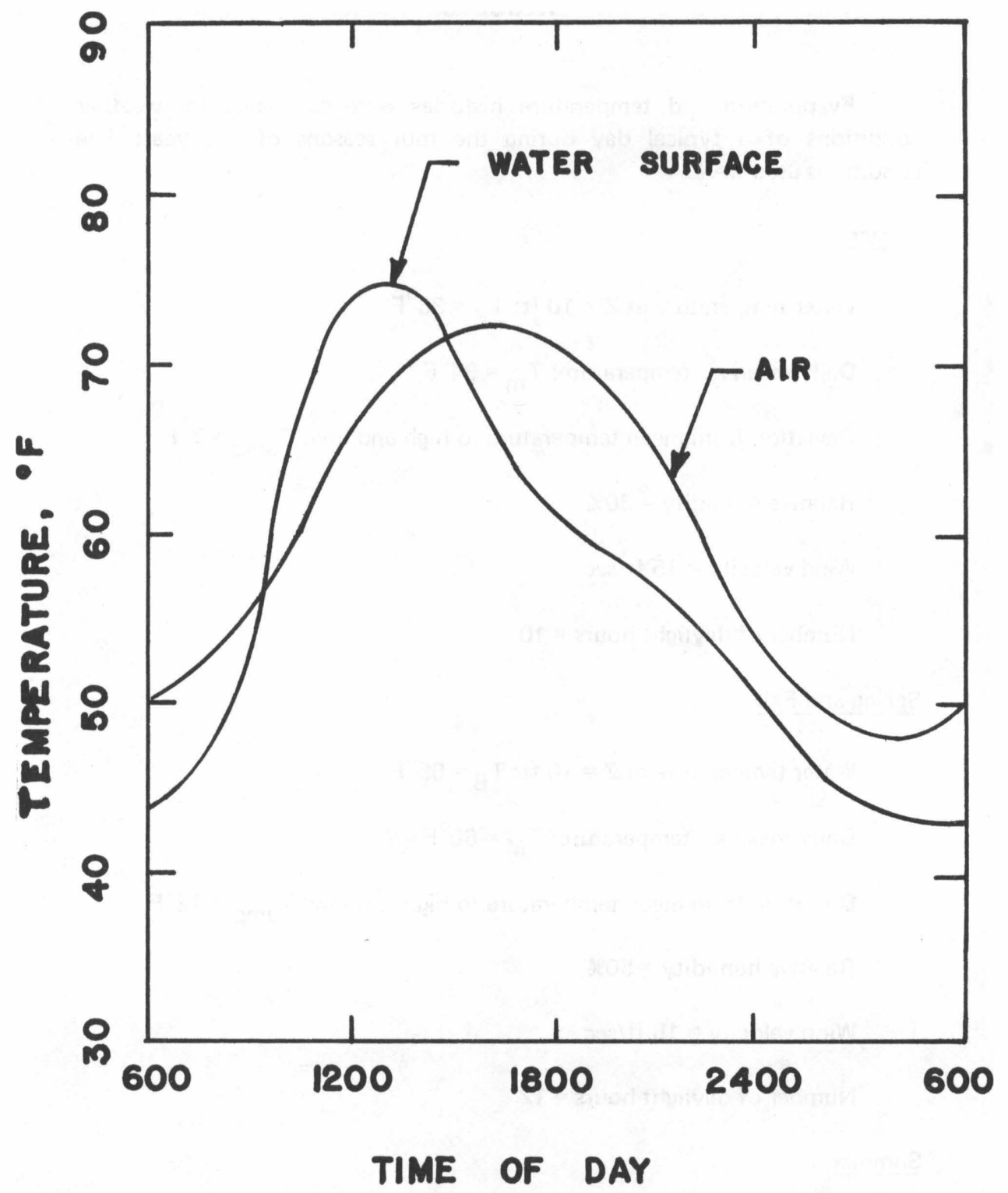

Figure 3. Temperatures for a Winter Day. 
Deviation from mean temperature to high and low: $\mathrm{T}_{\mathrm{amp}}=10^{\circ} \mathrm{F}$

Relative humidity $=50 \%$

Wind velocity $=15 \mathrm{ft} / \mathrm{sec}$

Number of daylight hours $=14$

A typical temperature history curve is shown in Figure 3. Although the temperature fluctuations are large, the trends indicated compare well with experimental work at Lake Hefner (14). Analytical results are presented in Table 2 showing the effects on water evaporation caused by a chemical monolayer that:

1. decreases the coefficient of water vapor diffusion into air,

2. decreases the shear stress on the water surface,

3. increases solar energy reflectance.

Table 3 shows the precent of evaporation reduction obtained by comparing evaporation from the monolayer-covered water surface with the evaporation of a water surface without a monolayer.

Using the properties of a cetyl alcohol monolayer, calculated values for evaporation reduction were compared with the experimental results of Crow (2). During a 66-day test period from July to October, 1959, Crow obtained a 25 percent reduction using cetyl alcohol on ponds. He further noted that the water surface temperature with the monolayer was an average of $5.4^{\circ} \mathrm{F}$ higher than the surface temperature of a similar uncovered pond.

The analytical results found in Table 3, using the cetyl alcohol monolayer, show an average evaporation reduction of $22.6 \%$ for a similar seasonal period. Also, the water surface temperature increased an average of $5.2^{\circ} \mathrm{F}$ during the same seasonal period. These analytical results agree closely with Crow and verify the analytical model to be satisfactory for calculating evaporation suppression.

Figure 4 illustrates an average annual evaporation reduction for the monolayers given in Tables 2 and 3 . The percent of evaporation reduction is plotted as a function of the normal reflectance ${ }^{1}$ ratio. This normal

\footnotetext{
${ }^{1}$ Normal reflectance is the solar energy reflectance when the sun is at the zenith $\left(\beta=0^{\circ}\right)$.
} 


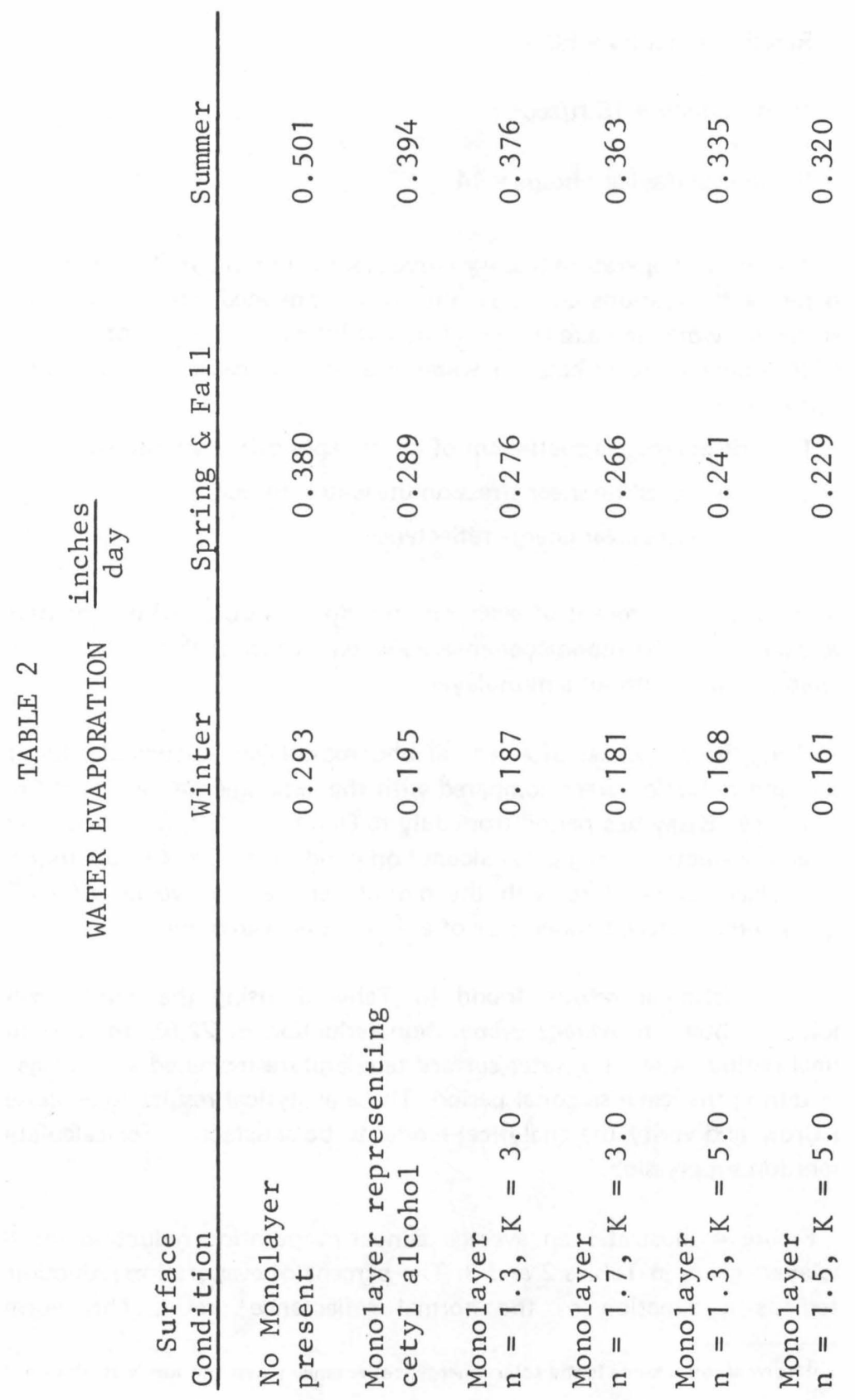




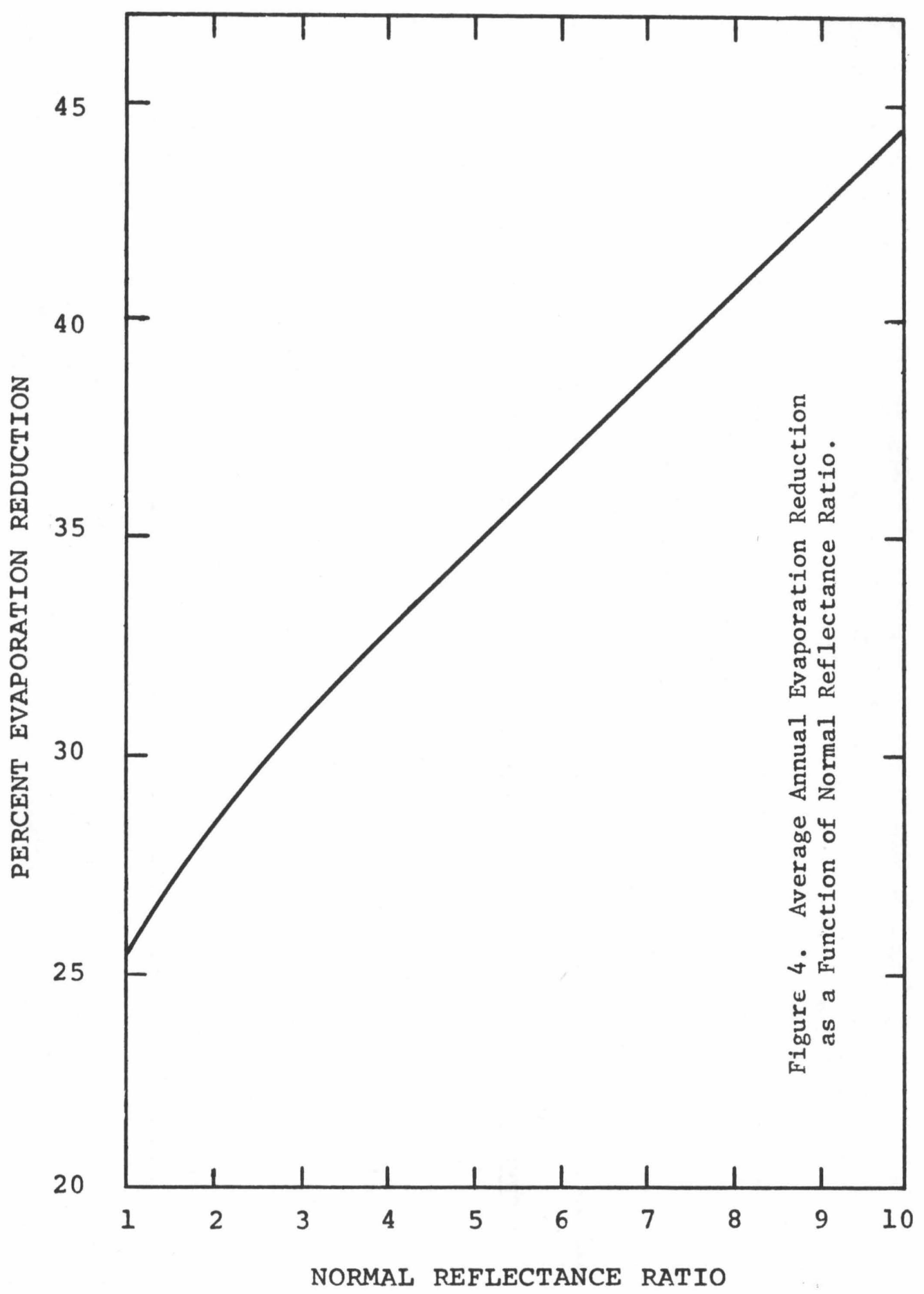




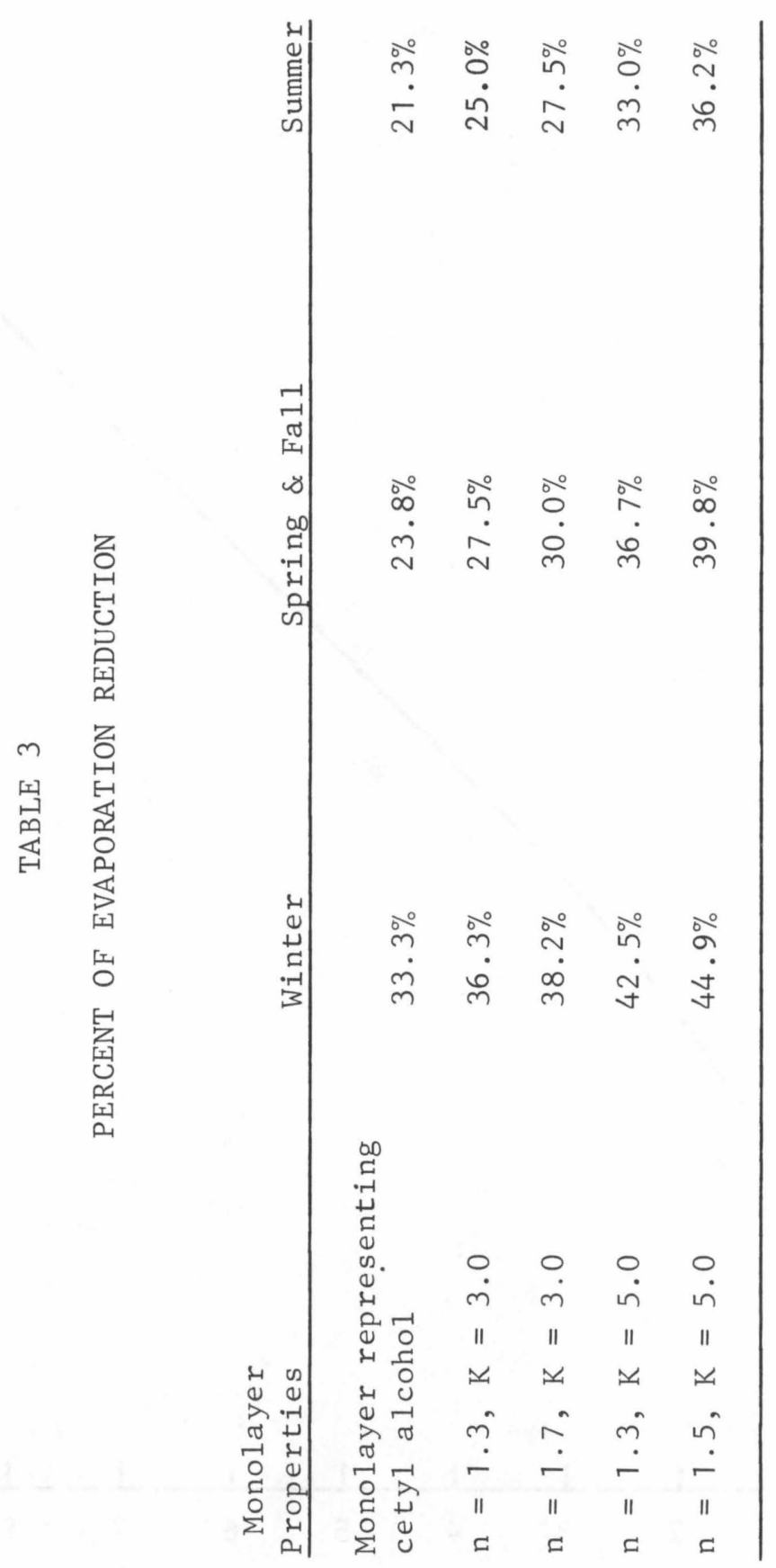


reflectance ratio is the normal reflectance of a monolayer-covered water surface divided by the normal reflectance of water.

Average annual evaporation reduction results showed values ranging from $25 \%$ to $45 \%$. These results demonstrate that water evaporation is significantly reduced by increasing the solar energy reflectance properties of monolayers. 


\section{CONCLUSIONS AND RECOMMENDATIONS}

The basic purpose of this study was to analytically determine the influence of solar radiation reflectance on water evaporation.

An analytical solution for water evaporation was presented. Water was assumed to act as a homogeneous solid slab undergoing conduction heat transfer. Boundary conditions were established and a transient numerical solution was used to find the temperature of the water reservoir as it varies with time. Evaporation was calculated for an ideal day during the four seasons. Analytical results of evaporation reduced by chemical monolayers were presented. In computing evaporation with a monolayer present, the diffusion coefficient, water shear stress, and solar radiation reflectance were changed. The results in Table 2 show that water evaporation is decreased by increasing the solar energy reflectance on monolayers and establish the advantage of a highly reflecting monolayer for evaporation suppression. The search for such a monolayer is the topic of a later paper.

It is recommended that future studies be made to determine the convection coefficient, and wind shear stress of monolayers. This will increase the accuracy of evaporation calculations. 


\section{LITERATURE CITED}

1. Harbeck, G. E., and Koberg, G. E. 1959. A Method of Evaluating the Effect of a Monomolecular Film in Suppressing Reservoir Evaporation. Journal of Geophysical Research. 64:89.

2. Crow, F. R. 1961. Reducing Reservoir Evaporation. Agricultural Engineering. 42:240-243.

3. La Mer, V. K. 1963. The Case for Evaporation Suppression. Chemical Engineering. 213-214.

4. Beard, J. T., and Wiebelt, J.A. 1966. Reflectance of Film-Covered Water Surfaces as Related to Evaporation Suppression. Journal of Geophysical Research. 71:3835.

5. Lapworth, C. F. 1965. Evaporation from Reservoirs Near London. Institution of Water Engineers. 19:163-181.

6. Ferguson, J. 1952. The Rate of Evaporation from Shallow Ponds. Australian Journal of Scientific Research. 5:315-330.

7. Cummings, N. W. 1950. Minimum Evaporation from Water Surfaces. American Geophysical Union-Transactions. 31:757-762.

8. Van der Held, E. F. M. 1952. Evaporation of a Free Water Surface Into a Stream of Air. Ingenieur. 64:89-94.

9. Bowen, I. S. 1926. The Ratio of Heat Losses by Conduction and by Evaporation from Any Water Surface. Physical Review. 27:779-787.

10. Holzman, B. 1941. The Heat-Balance Method for the Determination of Evaporation from Water Surfaces. Transactions of the . American Geophysical Union. 22:655-660.

11. Penman, H. L. 1946-1947. Evaporation in Nature. Report on Progress in Physics. Physical Society of London. 11:336-388. 
12. Sverdrup, H. U. 1945. Oceanography for Meteorologists. New York: Prentice Hall.

13. Koberg, G. E. 1964. Methods to Compute Long-Wave Radiation from the Atmosphere and Reflected Solar Radiation from a Water Surface. U.S. Geogical Survey Professional Paper 272-F. Washington, D. C.: U. S. Government Printing Office.

14. Water Loss Investigation: Lake Hefner Studies, Technical Report. 1954.

U.S. Geological Survey Professional Paper 269. Washington, D. C.: U.S. Government Printing Office.

15. Water Loss Investigations: Lake Mead Studies. 1958. U.S. Geological Survey Professional Paper 289. Washington, D. C.: U.S. Government Printing Office.

16. Brown, R. A., Peace, R. L., and McVehil, G. E. 1967. A Study of Hydrologic and Energy Budgets of Lake Erie with. Emphasis on Evaporation Measurements. Cornell Aeronautical Laboratory, Inc. CAL Report No. RM-2342-0-3. 27-28.

17. Schneider, P. J. 1957. Conduction Heat Transfer. Massachusetts: Addison-Wesley Publishing Company, Inc.

18. Hollen, D. K. 1968. The Influence of Solar Radiation Reflectance on Water Reflectance. A Master's Thesis. University of Virginia.

19. Wiebelt, J. A., and Beard, J. T. 1966. Study of the Radiant Properties of Monolayer Covered Water Storage Systems. U.S. Department of the Interior Bureau of Reclamation, Contract No. 14-06-D-5232., 23-24.

20. Keulegan, G. H. 1951. Wind Tides in Small Closed Channels. Journal of Research of the National Bureau of Standards. 46:358-381.

21. Fitzgerald, L. M. 1963. Wind-Induced Stresses on Water Surfaces, A Wind-Tunnel Study. Australian Journal of Physics. 16:475-489.

22. Hutchinson, G. E. 1957. A Treatise on Limnology. New York: John Wiley and Sons, Inc. I:273-276. 
23. Eckert, E. R. G., and Drake, R. M. 1959. Heat and Mass Transfer. New York: McGraw-Hill Book Company, Inc. 


\section{ACKNOWLEDGMENTS}

This work was done at the University of Virginia under joint sponsorship by the Virginia Water Resources Research Center through Grant No. A-019-VA and by the U.S. Bureau of Reclamation through Contract No. 14-06-D-6385. 
WATER RESOURCES RESEARCH CENTER

VIRGINIA POLYTECHNIC INSTITUTE BLACKSBURG, VIRGINIA 24061 